\title{
The Metabolism of ${ }^{35}$ S-labelled 2-Thiolhistidine and Ergothioneine in the Rat
}

\author{
BY H. HEATH* \\ Department of Chemical Pathology, University College Hospital Medical School, \\ London, W.C. 1
}

(Received 3 December 1952)

The origin and function of ergothioneine in blood are unknown; its presence, however, is well established (see Heath, Rimington, Searle \& Lawson, 1952, for a general review). Until the discovery by Leone \& Mann (1951) of ergothioneine in the seminal vesicle secretion of the boar, the only report of ergothioneine in animals was in blood cells. Seminal ergothioneine is present in high concentration, $40 \mathrm{mg}$./ $100 \mathrm{ml}$. of vesicular secretion as opposed to $6 \mathrm{mg}$./ $100 \mathrm{ml}$. in whole blood. Although blood ergothioneine has been shown to be present in all species so far examined, seminal ergothioneine appears to be limited to one species.

Spicer, Wooley \& Kessler (1951) have shown that when rabbits are reared on a controlled diet, the blood is nearly or completely devoid of ergothioneine; but when the diet is supplemented with either ergothioneine or liver extract then increased ergothioneine blood levels are observed. Heath et al. (1952) have also shown that dietary ergothioneine appears in the red cells of rats. The incorporation was found to be gradual, possibly occurring during erythropoiesis, and was not due to diffusion of ergothioneine from the plasma into the cells. Evidence that a diet, not containing added ergothioneine, can affect the ergothioneine content of the blood has been produced by Potter \& Franke (1935) for rats and by Eagles \& Vars (1928) for pigs. Spicer et al. (1951) have shown that the ergothioneine content of rabbit blood bears a relationship to the rate of formation and reversion of methaemoglobin after treatment of the erythrocytes with sodium nitrite.

Recent studies of the racial differences in the level of blood ergothioneine have been made by Fraser (1951) and by Touster \& Yarbro (1952). Eskimos, Canadian Indians and Negroes all have higher levels than a white population. Fraser (1951) precluded the possibility of a dietary effect. Touster \& Yarbro (1952) report lower blood levels in infants than adults, and are in agreement with Fraser (1951) that there is no significant variation at other ages.

Ergothioneine is the betaine of 2-thiolhistidine, and the latter compound could be its biological

* Address during 1953: The Lankenau Institute for Cancer Research, Philadelphia 11, Pa., U.S.A. precursor. Thiolhistidine has never been isolated from natural material but it has been synthesized by Ashley \& Harington (1930) and Harington \& Overhoff (1933). Eagles \& Vars (1928) suggested that maize might contain thiolhistidine as a precursor of ergothioneine, but Hunter (1951) failed to find any precursor of ergothioneine in maize. Ashley \& Harington (1930) also failed to find thiolhistidine in zein. The only report of the possible natural occurrence of thiolhistidine is by Lefevre \& Rangier (1942) who showed that $12 \%$ of the unidentified sulphur in horse serum proteins was pre. cipitated with mercuric chloride and oxidized to sulphate with bromine water, both properties being characteristic of 2-thiolhistidine.

The synthesis of ergothioneine by Heath, Lawson \& Rimington (1951) has made possible the preparation of isotopically labelled ergothioneine. This has now been used to study further the effect of feeding ergothioneine to rats. ${ }^{25} \mathrm{~S}$-labelled 2-thiolhistidine has also been prepared to see whether this compound can be methylated in vivo to yield ergothioneine, or whether it can be metabolized in any other way by the rat.

\section{MATERIALS AND METHODS}

[35S]2-Thiolhistidine and ergothioneine. These were synthesized by the method of Heath et al. (1951) using $25 \mathrm{~g}$. $\mathrm{KCN}^{25} \mathrm{~S}$ containing $10 \mathrm{mc}$. ${ }^{25} \mathrm{~S}$, obtained from the Radiochemical Centre, Amersham.

Perchloric acid mixture. 1 vol. $60 \% \mathrm{HClO}_{4}+3$ vol. $70 \%$ $\mathrm{HNO}_{2}$.

'Carrier' $\mathrm{H}_{2} \mathrm{SO}_{4}$. 0.01714 N- $\mathrm{H}_{2} \mathrm{SO}_{4}$, standardized gravimetrically so that $25 \mathrm{ml}$. yielded $50 \mathrm{mg}$. $\mathrm{BaSO}_{4}$.

Animals. Albino rats (100 g.) were used. These were fed a standard pellet diet (diet 41, Associated London Flour Millers Ltd., Bankside House, London, E.C. 3) and tap water, ad lib., and weighed daily.

Administration of (a) [ $\left.{ }^{35} \mathrm{~S}\right] 2$-thiolhistidine and (b) [ $\left.{ }^{35} \mathrm{~S}\right]-$ ergothioneine. (a) Three male rats were allowed a $40 \mathrm{mg}$./ $100 \mathrm{ml}$. solution of [ ${ }^{25}$ S] thiolhistidine in tap water $a d$ lib. for 21 days (the total weight of thiolhistidine ingested was $400 \mathrm{mg}$. containing $200 \mu \mathrm{c}$. [ $\left.\left.{ }^{86} \mathrm{~S}\right]\right)$. (b) Two male rats and one female were allowed a $25 \mathrm{mg}$. $/ 100 \mathrm{ml}$. solution of [ $\left.{ }^{85} \mathrm{~S}\right]$ ergothioneine in tap water $a d$ lib. for 21 days (the total weight of ergothioneine ingested was $250 \mathrm{mg}$. containing $125 \mu \mathrm{c}$. $\left.\left[{ }^{25} \mathrm{~S}\right]\right)$. 
Control rats were kept in all experiments. Urine and faeces were collected daily, and at the end of 21 days all rats were given tap water ad lib. in place of the radioactive solutions. The urine was examined daily for radioactivity and when this had reached a constant low level the rats were chloroformed and blood immediately removed from the heart and treated with heparin.

Determination of ergothioneine in blood. Ergothioneine was determined by the method of Hunter (1949) incorporating the modification of Fraser (1951). Whole blood (2 ml.) was used and the value per $100 \mathrm{ml}$. corpuscles calculated from the haematocrit.

Determination of ergothioneine in urine and tissues. Ergothioneine wás determined as described by Heath et al. (1952), except that the colour intensities were determined at a wavelength of $525 \mathrm{~m} \mu$. with a Unicam diffraction grating spectrophotometer.

Determination of ${ }^{25} \mathrm{~S}$ distribution in tissues. Except in the cases of blood, bone marrow and hair, either the whole organ (if the wet weight was less than $1 \mathrm{~g}$.) or $1 \mathrm{~g}$. of a representative sample of larger organs was rinsed with $0.9 \%$ $(w / v) \mathrm{NaCl}$ to remove surface blood, prior to wet oxidation. Blood. The total volume of blood $(3-5 \mathrm{ml}$.) remaining after ergothioneine and haematocrit determinations was separated into cells and plasma. The cells were washed seven times with $5 \mathrm{ml}$. portions of $0.9 \%(\mathrm{w} / \mathrm{v}) \mathrm{NaCl}$, the first washing being added to the plasma fraction. Bone marrow. After removal of all tissue from the limbs, the bones were crushed and extracted with $15 \mathrm{ml}$. water. Hair. The hair was shaved from the back and washed thoroughly with hot soap solution; $\mathbf{0 . 3}$ g. dried hair was used.

The material prepared as described above was refluxed for $18 \mathrm{hr}$. with $15 \mathrm{ml}$. perchloric acid mixture and $0.1 \mathrm{~g} . \mathrm{Cu}$ wire in $50 \mathrm{ml}$. Kjeldahl flasks. The solutions were evaporated, the residues dissolved in $4 \mathrm{ml} .6 \mathrm{~N}-\mathrm{HCl}$ and again evaporated to dryness, redissolved in $15 \mathrm{ml}$. boiling water with the addition (if necessary to effect complete solution) of $0.1 \mathrm{ml} .6 \mathrm{~N}-\mathrm{HCl}$. 'Carrier' $\mathrm{H}_{2} \mathrm{SO}_{4}(10 \mathrm{ml}$.) was added to the solutions thus obtained from the heart, lung, pancreas, kidney, spleen, eyes, tongue, brain, testis, bone marrow and seminal vesicle. The total sulphate ions were then precipitated as $\mathrm{BaSO}_{4}$, collected and washed in tared $10 \mathrm{ml}$. centrifuge tubes and, after drying at $105^{\circ}$ and reweighing, samples were transferred with $50 \%$ ethanol to tared nickel planchets. The activity was determined with an endwindow counter at infinite thickness.

Fractionation of urinary sulphur. The radioactivity of the urine was too great to determine without dilution; the following method was adopted in all cases. Free sulphate. $1 \mathrm{ml}$. urine was mixed with $25 \mathrm{ml}$. 'carrier' $\mathrm{H}_{2} \mathrm{SO}_{4}, 10 \mathrm{ml}$. $3 \times-\mathrm{HCl}$ and $10 \mathrm{ml}$. $5 \%(\mathrm{w} / \mathrm{v}) \mathrm{BaCl}_{2}$. The precipitated BaSO, was collected as described above. Ethereal sulphate. The supernatants and washings from the free sulphate determinations were filtered through Whatman no. 42 papers, $25 \mathrm{ml}$. 'carrier' $\mathrm{H}_{2} \mathrm{SO}_{4}$ added to. each and the mixture boiled for $30 \mathrm{~min}$. The $\mathrm{BaSO}_{4}$ samples were collected in tared $10 \mathrm{ml}$. centrifuge tubes, washed successively with water, $2 \mathrm{~N}-\mathrm{NaOH}$ and water until neutral. The $\mathrm{BaSO}_{4}$ was dried and transferred to planchettes as described above. Bromine-oxidizable sulphur. The supernatant liquids and washings (prior to the $\mathrm{NaOH}$ wash) were filtered through Whatman no. 42 papers, $25 \mathrm{ml}$. 'carrier' $\mathrm{H}_{2} \mathrm{SO}_{4}$ and $2 \mathrm{ml}$. $\mathrm{Br}$ were added to each and after $30 \mathrm{~min}$. excess $\mathrm{Br}$ was removed by boiling. The $\mathrm{BaSO}_{4}$ was collected as for ethereal sulphates. Total sulphur. Urine (1 ml.) was oxidized with perchloric acid mixture as described above, $25 \mathrm{ml}$. 'carrier' $\mathrm{H}_{2} \mathrm{SO}_{4}$ were added and $\mathrm{BaSO}_{4}$ collected as for 'free sulphate'.

Fractionation of artificial mixtures. The following solutions were fractionated as described above: $(a) 1 \mathrm{ml}$. $\mathrm{H}_{2}{ }^{35} \mathrm{SO}_{4}$ (a suitable dilution of a solution obtained from the Atomic Energy Research Establishment, Harwell) $+45 \mathrm{mg}$. inactive thiolhistidine, (b) $1 \mathrm{ml}$. [ $\left.{ }^{85} \mathrm{~S}\right]$ thiolhistidine solution (as administered to the rats), (c) $1 \mathrm{ml}$. [ $\left.{ }^{85} \mathrm{~S}\right]$ ergothioneine solution (as administered to the rats).

Fractionation of sulphur in liver and kidney from rats fed with [ ${ }^{25}$ S] ergothioneine. The bulked residues (20 g.) of 3 livers after ergothioneine and total $S$ determinations were ground and suspended in water $(100 \mathrm{ml}$.) in a homogenizer and mixed with ethanol $(100 \mathrm{ml}$.). After centrifugation, the clear supernatant solution was evaporated to dryness under reduced pressure. The residue was extracted with $2 \mathrm{ml}$. $2.3 \%(w / v)$ sulphosalicylic acid, filtered and made up to $3 \mathrm{ml}$. with water. $1 \mathrm{ml}$. of this solution was fractionated as described above for urine. The ethanol-precipitated protein was washed with $50 \%(v / v)$ ethanol, dried, and $0.5 \mathrm{~g}$. oxidized with perchloric acid mixture. The BaSO, was isolated as described above but without the addition of carrier. The bulked residues ( 1 g.) of the kidneys of the three ergothioneine-fed rats were treated in the same way.

Paper chromatography. Extracts from the livers of normal, ergothioneine and thiolhistidine fed rats, made as described above were fractionated by single-dimension paper chromatography using butanol/acetic acid/water mixtures (50:10:40). Owing to the high concentration of soluble material other than ergothioneine the identification of the ergothioneine on the chromatograms was made by adding $30 \mu \mathrm{g}$. of ergothioneine to an equal portion of each extract and using this solution as a reference marker. The position of the ergothioneine after development of the chromatograms was found by spraying with either a $0.4 \%$ (w/v) ethanolic solution of 2:6-dichloroquinone chloroimide (British Drug Houses Ltd.) or by an equal mixture of the buffer and diazo solutions described by Hunter (1951), followed by $2 \mathrm{~N}-\mathrm{NaOH}$.

\section{RESULTS}

As one object was to ascertain whether the sulphur of 2-thiolhistidine was utilized by the rat, it was essential to be certain that circulating thiolhistidine, which was in process of elimination, was not confused with any thiolhistidine permanently incorporated into the system.

\section{Distribution of ${ }^{35} \mathrm{~S}$ in urine}

As can be seen from Table 1, 4 days after discontinuing the administration, the radioactivity in all fractions of the urine was negligible; the first thiolhistidine rat was killed on the 29th day of the experiment.

The bromine-oxidizable sulphur fraction, which represents the unchanged mercaptoglyoxaline nucleus of thiolhistidine accounts on the 21st day for approximately $90 \%$ of the total radioactivity and the free sulphates and ethereal sulphates, which are some indication of the degree of metabolism, for 5 and $1 \%$ respectively. 
A similar experiment on the urinary excretion of $\left[{ }^{35}\right.$ S] $]$ rgothioneine was also carried out.

Table 1. Radioactivity of $\mathrm{BaSO}_{4}$ (counts/min. in 1 sq.cm. samples of infinite thickness) prepared by fractionation of the sulphur-containing constituents of the urine obtained from rats maintained on a diet containing $\left.{ }^{35} \mathrm{~S}\right]$ thiolhistidine

\begin{tabular}{|c|c|c|c|c|}
\hline $\begin{array}{l}\text { Days from } \\
\text { commence- } \\
\text { ment of } \\
\text { feeding }\end{array}$ & Total S & $\begin{array}{c}\text { Free } \\
\text { sulphate }\end{array}$ & $\begin{array}{l}\text { Ethereal } \\
\text { sulphate }\end{array}$ & $\begin{array}{c}\text { Bromine- } \\
\text { oxidizable } \\
\text { S }\end{array}$ \\
\hline $\begin{array}{r}1 \\
20\end{array}$ bulked & 747 & 44 & 10 & 911 \\
\hline 21 & 788 & 50 & 13 & 959 \\
\hline $22^{*}$ & 401 & 50 & 15 & 420 \\
\hline 23 & 53 & 10 & 1 & 43 \\
\hline 24 & 13 & 0 & 4 & 13 \\
\hline 25 & 4 & 0 & 1 & 2 \\
\hline 26 & 3 & 0 & 0 & 5 \\
\hline
\end{tabular}

* [ ${ }^{25}$ S]Thiolhistidine was fed continuously for 21 days and discontinued from the 22nd day onwards. No ergothioneine could be detected colorimetrically in the urine.

Table 2. Radioactivity of $\mathrm{BaSO}_{4}$ (counts/min. in 1 sq.cm. samples of infinite thicloness) prepared by fractionation of the sulphur-containing constituents of the urine obtained from rats maintained on a diet containing $\left[{ }^{35} S\right]$ ergothioneine

\begin{tabular}{|c|c|c|c|c|}
\hline $\begin{array}{l}\text { Days from } \\
\text { commence- } \\
\text { ment of } \\
\text { feeding }\end{array}$ & Total S & $\begin{array}{c}\text { Free } \\
\text { sulphate }\end{array}$ & $\begin{array}{l}\text { Ethereal } \\
\text { sulphate }\end{array}$ & $\begin{array}{l}\text { Bromine- } \\
\text { oxidizable } \\
\mathrm{S}\end{array}$ \\
\hline 1) bulked & 180 & 63 & 9 & 136 \\
\hline 21 & 211 & 71 & 10 & 169 \\
\hline $22^{*}$ & 97 & 28 & 1 & 104 \\
\hline 23 & 19 & 3 & i & 16 \\
\hline 24 & 18 & 5 & 2 & 16 \\
\hline 25 & 12 & 5 & 6 & 10 \\
\hline 26 & 14 & 1 & 3 & 8 \\
\hline
\end{tabular}

* [ $\left.{ }^{35} \mathrm{~S}\right]$ Ergothioneine was fed continuously for 21 days and discontinued from the 22nd day onwards. The bulked urine (days 1-20) contained 12 mg. ergothioneine/ $100 \mathrm{ml}$.

As shown in Table 2 the radioactivity fell considerably when the administration was discontinued, although not to such an extent as in the thiolhistidine experiment. The bromine-oxidizable sulphur fraction accounts for $60 \%$ of the total radioactivity and the free and ethereal sulphates for 35 and $4 \%$ respectively.

In order to prove that this method of sulphur fractionation was valid and coprecipitation did not occur, mixtures of $\mathrm{H}_{2}{ }^{35} \mathrm{SO}_{4}$ and thiolhistidine, $\mathrm{H}_{2} \mathrm{SO}_{4}$ and $\left[{ }^{35} \mathrm{~S}\right]$ thiolhistidine, and also of $\mathrm{H}_{2} \mathrm{SO}_{4}$ and [35] ${ }^{35}$ ergothioneine were fractionated by the game method. In all cases good separation was obtained (Table 3). The $\mathrm{BaSO}_{4}$ derived from the free sulphate

Table 3. Radioactivity of $\mathrm{BaSO}_{4}$ (counts/min. in 1 sq.cm. samples of infinite thickness) prepared from mixtures of active and non-active ergothio. neine, thiolhistidine and $\mathrm{H}_{2} \mathrm{SO}_{4}$

$$
\begin{gathered}
\text { Constituents of } \\
\text { mixture }
\end{gathered}
$$

[ $\left.{ }^{25} \mathrm{~S}\right]$ Thiolhistidine $+\mathrm{H}_{8} \mathrm{SO}_{4}$ [35] Ergothioneine $+\mathrm{H}_{2} \mathrm{SO}_{4}$ Thiolhistidine $+\mathrm{H}_{2}{ }^{25} \mathrm{SO}_{4}$

$\begin{array}{ccc}\text { Free } & \text { Ethereal } & \begin{array}{c}\text { Bromine- } \\ \text { oxidizable }\end{array} \\ \text { sulphate } & \text { sulphate } & \text { S } \\ 0 & 0 & 541 \\ 0 & 0 & 182 \\ 428 & 0 & 0\end{array}$

was not contaminated with any $\left[{ }^{35} \mathrm{~S}\right]$ thiolhistidine or $\left.{ }^{35} \mathrm{~S}\right]$ ergothioneine, nor was either of these com. pounds oxidized to sulphate, during the procedure for hydrolysis of ethereal sulphate.

\section{Ergothioneine in tissues}

The results of the colorimetric determinations of ergothioneine in blood and tissues are shown in Table 4.

All rats were fed for 21 days with either ergothioneine or thiolhistidine. Owing to practical limitations only one rat was killed at a time and complete analyses were carried out. As shown in Table 4 the feeding of thiolhistidine does not cause any increase in blood ergothioneine level, but ergothioneine is present in the liver and kidney.

\section{Table 4. Ergothioneine distribution in rats maintained for 21 days on a diet containing} either ergothioneine or thiolhistidine

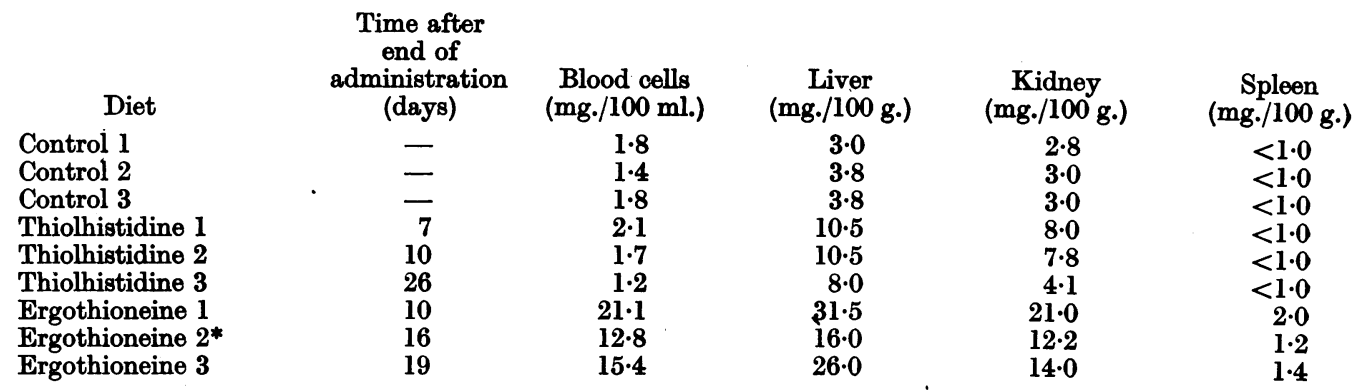

* Ergothioneine-fed rat no. 2 was pregnant at the time of death. 
Administered ergothioneine causes an increase in the blood level from a mean value of $1.7 \mathrm{mg} . / 100 \mathrm{ml}$. to as high a value as $21.1 \mathrm{mg} . / 100 \mathrm{ml}$. The increase in the liver and kidney is also much more pronounced than in the case of the thiolhistidine experiment.

No ergothioneine was found in the seminal vesicles or testes of any of the rats. The placenta of the pregnant female ergothioneine-fed rat contained $6 \mathrm{mg}$./100 g. of ergothioneine, but no ergothioneine could be detected in the foetuses.

The distribution of ${ }^{25} \mathrm{~S}$ in the rats after administration of $\left.{ }^{35} \mathrm{~S}\right]$ thiolhistidine and $\left.{ }^{25} \mathrm{~S}\right]$ ergothioneine is given in Table 5.

The very low activities recorded for the rats fed ${ }^{285}$ S $]$ thiolhistidine show conclusively that the sulphur of thiolhistidine is not permanently utilized in the metabolism of the rat.
In the ergothioneine experiment some radioactivity was found in all organs. There was high activity in the blood cells, and although surface blood was removed by washing with $0.9 \%(w / v)$ sodium chloride prior to oxidation, sufficient blood probably remained in the tissue to account for the radioactivity found in the eyes, tongue, muscle, pancreas, brain, foetus, placenta, testis and epididymis, seminal vesicle and spleen. Radioactivity of the barium sulphate obtained from the heart and lungs was too great to be accounted for in this manner (ergothioneine, however, was not estimated colorimetrically in the heart and lungs). Besides incorporation in the blood cells (compare Table 4) ergothioneine is without doubt accumulated by the bone marrow, liver and kidney.

The radioactivity due to the ergothioneine present in the liver, kidney and blood cells of the $\left.{ }^{35} \mathrm{~S}\right]$ ergo-

Table 5. Radioactivity of $\mathrm{BaSO}_{4}$ (counts/min. in 1 sq.cm. samples of infinite thickness) prepared from the total sulphur of tissues obtained from rats maintained for 21 days on a diet containing [ ${ }^{35}$ S]thiolhistidine or $\left[{ }^{25} \mathrm{~S}\right]$ ergothioneine

(Values are corrected for added carrier, background and decay. The figures in brackets are the number of days after the last day of administration of ergothioneine or thiolhistidine before the rats were killed. No correction has been made for the sulphur content of the very small amount of heparin used.)

\begin{tabular}{|c|c|c|c|c|c|c|}
\hline \multirow[b]{2}{*}{ Organ } & \multicolumn{3}{|c|}{ Rats on [ $\left.{ }^{35} \mathrm{~S}\right]$ ergothioneine diet } & \multicolumn{3}{|c|}{ Rats on $\left[{ }^{85} \mathrm{~S}\right]$ thiolhistidine diet } \\
\hline & Rat $1(10)$ & Rat $2^{*}(16)$ & Rat 3 (19) & Rat 1 (7) & Rat. $2(10)$ & Rat $3(26)$ \\
\hline Liver & 671 & 286 & 480 & $\mathbf{0}$ & 2 & 2 \\
\hline Kidney & 425 & 190 & 195 & 8 & 3 & 0 \\
\hline Blood cells & 408 & 242 & 301 & 4 & 1 & $\mathbf{0}$ \\
\hline Bone marrow & 229 & 134 & 174 & 0 & 0 & 1 \\
\hline Placenta & - & 120 & & - & - & - \\
\hline Lungs & 177 & 107 & 122 & 5 & $\mathbf{0}$ & 2 \\
\hline Heart & 90 & 64 & 71 & 3 & 0 & 0 \\
\hline Testes and epididymis & 66 & - & 41 & 7 & 2 & 2 \\
\hline Spleen & 48 & 91 & 69 & 0 & 0 & 0 \\
\hline Blood plasma & 43 & 12 & 22 & 2 & 2 & $\mathbf{0}$ \\
\hline Muscle & 39 & 79 & 41 & 2 & 0 & 4 \\
\hline Tongue & 38 & 25 & 24 & 0 & 6 & 0 \\
\hline Foetus & . & 22 & - & - & - & - \\
\hline Brain & 26 & 14 & 25 & 3 & $\mathbf{0}$ & $\mathbf{0}$ \\
\hline Pancreas & 26 & 24 & 26 & 0 & 0 & 0 \\
\hline Seminal vesicles & 26 & - & 43 & 0 & 0 & 0 \\
\hline Eyes & 17 & 8 & 9 & $\mathbf{0}$ & 0 & 0 \\
\hline Hair & 5 & 1 & 4 & 7 & 1 & 0 \\
\hline Faeces & - & - & $\overline{7}$ & - & - & 0 \\
\hline
\end{tabular}

* This rat was pregnant at time of death.

Table 6. Comparison of the relative specific radioactivities of $\mathrm{BaSO}_{4}$ samples (counts/min. in 1 sq.cm. of infinite thickness) prepared from the total sulphur of the liver, kidney and blood cells of rats fed ${ }^{[55}$ ] $]$ rgothioneine with calculated radioactivities based on the content of ergothioneine* determined colorimetrically

\begin{tabular}{|c|c|c|c|c|c|c|}
\hline \multirow[b]{2}{*}{ Tissue } & \multicolumn{2}{|c|}{ Rat 1} & \multicolumn{2}{|c|}{ Rat 2} & \multicolumn{2}{|c|}{ Rat 3} \\
\hline & Found & Calculated & Found & Calculated & Found & Calculated \\
\hline $\begin{array}{l}\text { Liver } \\
\text { Blood cells } \\
\text { Kidney }\end{array}$ & $\begin{array}{l}671 \\
408 \\
425\end{array}$ & $\begin{array}{l}670 \\
417 \\
226\end{array}$ & $\begin{array}{l}286 \\
242 \\
190\end{array}$ & $\begin{array}{r}250 \\
267 \\
98\end{array}$ & $\begin{array}{l}480 \\
301 \\
195\end{array}$ & $\begin{array}{r}500 \\
330 \\
98\end{array}$ \\
\hline
\end{tabular}

* Ergothioneine (1 mg.) after oxidation and dilution with $\mathrm{H}_{2} \mathrm{SO}_{4}$ so as to yield $100 \mathrm{mg}$. $\mathrm{BaSO}_{4}$ had an activity of 494 counts/min./sq.cm. at infinite thickness. 
Table 7. Radioactivity of $\mathrm{BaSO}_{4}$ (counts/min. in 1 sq.cm. samples of infinite thickness) obtained by fractionation of the sulphur constituents of the liver and kidney of rats maintained for 21 days on a diet containing ${ }^{35}$ S] ergothioneine

(Values are corrected for background and added carrier.)

\begin{tabular}{|c|c|c|c|c|}
\hline \multirow[b]{2}{*}{ Fraction } & \multicolumn{2}{|c|}{ Liver } & \multicolumn{2}{|c|}{ Kidney } \\
\hline & Activity & $\begin{array}{c}\text { Total }{ }^{35 \mathrm{~S} \text { in }} \\
\text { ethanol extract } \\
(\%)\end{array}$ & Activity & $\begin{array}{c}\text { Total }{ }^{85 \mathrm{~S} \text { in }} \\
\text { ethanol extract } \\
(\%)\end{array}$ \\
\hline Total $S$ in protein & 10 & - & 8 & - \\
\hline Total $S$ in ethanol extract & 675 & 100 & 52 & 100 \\
\hline Free sulphate in ethanol extract & 0 & 0 & 102 & 9 \\
\hline Ethereal sulphate in ethanol extract & 0 & 0 & 0 & 0 \\
\hline Bromine-oxidizable $S$ in ethanol extract & 2925 & 97 & 132 & 75 \\
\hline
\end{tabular}

thioneine-fed rats was calculated from the relative specific activity of the ergothioneine administered and the amount of ergothioneine present, determined.colorimetrically.

As can be seen from Table 6, the ergothioneine present in the liver and blood cells accounts for all the radioactivity, but the ergothioneine present in the kidney accounts for only $50 \%$ of the activity. Confirmation of this was obtained by fractionation of the sulphur constituents of the aqueous 'homogenates' of the bulked residues of liver and kidney obtained from the three ergothioneine-fed rats. The results of these fractionations are shown in Table 7.

The radioactivity in the liver is therefore concentrated in the bromine-oxidizable sulphur fraction, whereas only $75 \%$ of the activity in the kidney is in the same fraction. The general conclusion which can be drawn from all the data concerning the ergothioneine-fed rats is that dietary ergothioneine without doubt accumulates in certain tissues, but its sulphur does not appear to be utilized for the synthesis of other sulphur-containing constituents.

In the various experiments no difference in growth rate was observed between experimental animals and controls.

\section{DISCUSSION}

The only suggested biological function of 2-thiolhistidine has been as a precursor of ergothioneine or of histidine (Eagles \& Vars, 1928; Neuberger \& Webster, 1946). The results recorded in this paper demonstrate that thiolhistidine is not a precursor of ergothioneine, at least in the case of the rat; after 21 days continuous administration of $\left[{ }^{35} \mathrm{~S}\right]$ thiolhistidine there was no increase in the blood ergothioneine level. That the thiolhistidine had been absorbed from the alimentary tract was clearly shown by the urine analyses; but the complete absence of any radioactivity in all the organs of the rats examined showed that the thiolhistidine was neither accumulated as such nor was the sulphur it contained used for the biosynthesis of other compounds. This result was not entirely unexpected, since thiolhistidine has never been shown to occur naturally even in the numerous studies of aminoacids in natural materials made during recent years by the sensitive method of paper chromatography.

The appearance of non-radioactive ergothioneine in liver after feeding [ ${ }^{35}$ S] thiolhistidine was most unexpected. Had the ergothioneine found in the liver been derived directly from the administered thiolhistidine, the relative specific activity of the barium sulphate isolated, would have been approximately 200 . The possibility that the radioactivity of the administered thiolhistidine was too low for the detection of activity in the liver can therefore be excluded. The evidence for the presence of ergothioneine depends upon the highly specific Hunter colour reaction. In all cases a characteristic magenta colour was obtained. The specificity of the Hunter reaction is discussed by Lawson, Morley \& Woolf (1951), and the only other compound found by these workers to give a positive Hunter reaction which could have been confused with that of ergothioneine was 2-mercaptourocanic acid which is formed from ergothioneine by the loss of trimethylamine. The possibility that the positive reactions of the liver extracts were given by 2 -mercaptourocanic acid can be ruled out, because this compound is not precipitated by the iodobismuthous acid used in the analytical procedure. Supporting evidence for the presence of ergothioneine in the liver extracts was given by paper chromatography.

No attempt is made here to account for the presence of inactive ergothioneine in the livers of rats fed with radioactive 2-thiolhistidine. However, one can at least tentatively suggest that the thiolhistidine activates a reaction mechanism involving the biosynthesis of ergothioneine. Some indication that thiolhistidine may have been in. volved in a metabolic reaction is given by the results of the urine analyses. Although $90 \%$ of the thiolhistidine was excreted unchanged, $5 \%$ of the sulphur was oxidized to sulphate.

In contrast to thiolhistidine, ergothioneine is absorbed and retained by the rat. This confirms the work of Heath et al. (1952) and Spicer et al. (1951) who fed non-isotopic ergothioneine to rats and 
rabbits respectively and obtained marked increases in blood ergothioneine levels.

Whether blood ergothioneine is endogenous or exogenous in origin is unknown. The fact that dietary ergothioneine is incorporated into the blood does not prove that blood ergothioneine is, in actual fact, of exogenous origin.

The hypothesis of Heath et al. (1952) that ergothioneine is incorporated into the blood during erythropoiesis is supported by the presence of radioactive ergothioneine in the bone marrow. LutwakMann (1952) has recently reported the presence of ergothioneine in the bone marrow of normal rats. The incorporation of ergothioneine into erythrocytes is not of a transient nature. This is shown by the abnormally high blood levels recorded 19 days after the administration of ergothioneine was stopped. The results of these experiments also confirm previous reports based on colorimetric evidence (Hunter, 1949), that blood ergothioneine is confined to the cellular fraction. The small amount of ${ }^{25} \mathrm{~S}$ present in the plasma was probably due to haemolysis.

The non-appearance of ergothioneine in the seminal vesicle is interesting in view of the results of Leone \& Mann (1951), who showed that ergothioneine was present in boar but absent from rat seminal-vesicular secretion. Thus it appears that if ergothioneine is not a normal constituent of the seminal vesicle of any particular species, then dietary ergothioneine will not be incorporated into this organ, and the non-occurrence of ergothioneine in these organs of normal rats cannot be due to a deficiency of ergothioneine in the diet.

In view of the interest shown in recent years in the effect of ergothioneine on the thyroid, it is interesting to note the non-accumulation of ergothioneine by the thyroid gland.

There is no evidence that the sulphur of ergothioneine is used in the biosynthesis of other com. pounds; all the radioactive sulphur of the liver can be accounted for by the ergothioneine present. On the other hand, $35 \%$ of the urinary ${ }^{85} \mathrm{~S}$ is in the form of sulphate, and the possibility that the residue of the ergothioneine molecule is used in biosynthesis must await ${ }^{14} \mathrm{C}$ experiments. The significance of ergothioneine accumulation in the liver is as yet unknown. No explanation of its function, based on these ${ }^{85} \mathrm{~S}$ studies, can be put forward. A fuller understanding of the metabolic function of this compound will probably be derived from similar studies with ergothioneine labelled in the methyl groups.

\section{SUMMARY}

1. $\left.{ }^{35} \mathrm{~S}\right] 2-T h i o l h i s t i d i n e$ and $\left[{ }^{35} \mathrm{~S}\right]$ ergothioneine were synthesized, and administered separately, in the diet, to rats for 21 days. The distribution of ${ }^{25} \mathrm{~S}$ and ergothioneine in the animals was determined after sufficient time had been allowed for the nonincorporated circulating material to be excreted.

2. The rate and pattern of urinary excretion was studied in both cases; $5 \%$ of the thiolhistidine and $35 \%$ of the ergothioneine sulphur was excreted as sulphate.

3. The sulphur of thiolhistidine and ergothioneine was not incorporated into other sulphur compounds of the rat.

4. There was no increase in the ergothioneine blood level after thiolhistidine administration, nor was there any accumulation of thiolhistidine in any tissue of the rat. It was concluded that thiol. histidine cannot be methylated by the rat to yield ergothioneine.

5. Dietary ergothioneine was incorporated into the blood cells, bone marrow, liver and kidney.

6. The presence of non-radioactive ergothioneine in the liver of rats after the administration of [ $\left.{ }^{35} \mathrm{~S}\right]$ thiolhistidine was observed.

7. The absence of ergothioneine from the seminalvesicular secretion of the rat (as opposed to the pig) is a true species difference and is not due to any deficiency of ergothioneine.

It is a pleasure for the author to acknowledge the technical assistance of Miss B. Tooth, and the interest and advice of Prof. C. Rimington.

\section{REFERENCES}

Ashley, J. N. \& Harington, C. R. (1930). J. chem. Soc. p. 2586.

Eagles, B. A. \& Vars, H. M. (1928). J. biol. Chem. 80, 615. Fraser, R. S. (1951). J. Lab. clin. Med. 37, 199.

Harington, C. R. \& Overhoff, J. (1933). Biochem. J. 27, 338.

Heath, H., Lawson, A. \& Rimington, C. (1951). J. chem. Soc. p. 2215.

Heath, H., Rimington, C., Searle, C. E. \& Lawson, A. (1952). Biochem. J. 50, 530.

Hunter, G. (1949). Canad. J. Res. 27, 230.

Hunter, G. (1951). Biochem. J. 48, 265.
Lawson, A., Morley, H. V. \& Woolf, L. I. (1951). Nature, Lond., 167, 82.

Lefevre, C. \& Rangier, M. (1942). C.R. Acad. Sci., Paris, 214, 774.

Leone, E. \& Mann, T. (1951). Nature, Lond., 168, 205.

Lutwak-Mann, C. (1952). Biochem. J. 52, 356.

Neuberger, A. \& Webster, T. A. (1946). Biochem. J. 40, 576.

Potter, V. R. \& Franke, K. W. (1935). J. Nutr. 9, 1.

Spicer, S. S., Wooley, J. G. \& Kessler, V. (1951). Proc. Soc. exp. Biol., N.Y., 77, 418.

Touster, 0. \& Yarbro, M. C. (1952). J. Lab. clin. Med. 39, 720. 